\title{
A novel algorithm for detection of precipitation in tropical regions using PMW radiometers
}

\author{
D. Casella, G. Panegrossi, P. Sanò, L. Milani, M. Petracca, and S. Dietrich \\ Consiglio Nazionale delle Ricerche - Istituto di Scienze dell'Atmosfera e del Clima (CNR-ISAC), Rome, Italy \\ Correspondence to: D. Casella (daniele.casella@ artov.isac.cnr.it)
}

Received: 3 August 2014 - Published in Atmos. Meas. Tech. Discuss.: 12 September 2014

Revised: 16 January 2015 - Accepted: 3 February 2015 - Published: 12 March 2015

\begin{abstract}
A novel algorithm for the detection of precipitation is described and tested. The algorithm is applicable to any modern passive microwave radiometer on board polar orbiting satellites independent of the observation geometry and channel frequency assortment. The algorithm is based on the application of canonical correlation analysis and on the definition of a threshold to be applied to the resulting linear combination of the brightness temperatures in all available channels. The algorithm has been developed using a 2-year data set of co-located Special Sensor Microwave Imager/Sounder (SSMIS) and Tropical Rainfall Measuring Mission precipitation radar (TRMM-PR) measurements and Advanced Microwave Sounding Unit (AMSU) Microwave Humidity Sounder and TRMM-PR measurements. This data set was partitioned into four classes depending on the background surface emissivity (vegetated land, arid land, ocean, and coast) with the same procedure applied for each surface class. In this paper we describe the procedure and evaluate the results in comparison with many well-known algorithms for the detection of precipitation.

The algorithm shows a small rate of false alarms and superior detection capability; it can efficiently detect (probability of detection between 0.55 and 0.71 ) minimum rain rate varying from $0.14 \mathrm{~mm} \mathrm{~h}^{-1}$ (AMSU over ocean) to 0.41 (SSMIS over coast) with the remarkable result of $0.25 \mathrm{mmh}^{-1}$ over arid land surfaces.
\end{abstract}

\section{Introduction}

The Global Precipitation Measurement mission (GPM) (Hou et al., 2014) started its operational phase on 28 February 2014 with the launch of the NASA/JAXA GPM Core Ob- servatory. The goal of the mission is to provide instantaneous precipitation measurements with a coverage of less than $1 \mathrm{~h}$ over $60 \%$ of the globe and less than $3 \mathrm{~h}$ over $80 \%$ of the globe through the exploitation of a constellation of passive microwave (PMW) radiometers on board research and operational satellites provided by the United States, Japan, France/India, and the European Community. The GPM Core Observatory carries the first spaceborne dualfrequency precipitation radar, the dual-frequency precipitation radar (DPR), operating at $\mathrm{Ku}$ and $\mathrm{Ka}$ bands (13 and $35 \mathrm{GHz}$, respectively) and a conical scanning multichannel $(10-183 \mathrm{GHz})$ microwave imager, the GPM Microwave Imager (GMI). The GPM constellation consists of radiometers with different scanning geometries (both conical and cross-track scanning), different assortments of multichannel frequencies and polarizations, and different spatial resolutions. The microwave imagers and sounders with a conical scanning observation geometry are (1) the Special Sensor Microwave Imager/Sounder (SSMIS), which measures microwave energy at 24 discrete frequencies from 19 to $183 \mathrm{GHz}$ (Kunkee et al., 2008), and (2) the Advanced Microwave Scanning Radiometer 2 (AMSR-2) (Shimoda, 2005) with channels ranging from 6.9 to $89 \mathrm{GHz}$. The cross-track scanners are (1) the Microwave Humidity Sounder (MHS) (89-190 GHz) on board the NOAA Polar-Orbiting Environmental Satellites (POES) and the EUMETSAT MetOp satellites (Edwards and Pawlak, 2000), (2) the Advanced Technology Microwave Sounder (ATMS) instrument on board the NPOESS NPP satellite (Muth et al., 2005) with 22 channels in the range of frequency $23.8-183 \mathrm{GHz}$, and (3) Sondeur Atmosphérique du Profil d'Humidité Intertropicale par Radiométrie (SAPHIR) with six channels in the $183 \mathrm{GHz}$ water vapor absorption band, carried by the French/Indian satellite 
Megha-Tropiques (Desbois et al., 2003). It is also worth mentioning the Advanced Microwave Sounding Unit-A (AMSUA), which is another cross-track scanner with 15 channels ranging from 23.8 to $89 \mathrm{GHz}$; this last instrument is not included in the official GPM constellation, but it is carried by the same satellites equipped with the MHS radiometer.

Obtaining coherent (and accurate) precipitation estimates from this assortment of instruments requires a robust intercalibration of the brightness temperatures (TBs). The GPM has established an international team called Intersatellite Calibration Working Group (X-CAL) in order to address this need (Wilheit, 2013). Moreover, the estimates themselves need to be obtained with common procedures and data sets. The 2014 version of the Bayesian-based Goddard PROFiling algorithm (GPROF2014) (Kummerow et al., 2001, 2011) will be applied to all passive microwave radiometers in the GPM constellation and it will be the official NASA PMW precipitation retrieval algorithm for GPM. However, the inconsistencies in the precipitation detection deriving from the use of different radiometers also might significantly affect the rainfall estimates from such a heterogeneous constellation and precipitation products derived from the combination of these estimates (i.e., IR/MW merging techniques). The differences in the available channels, polarization information, spatial resolutions, and observation geometry have a strong impact on the possibility of separating the radiance due to the background surface from the signal related to precipitation. Therefore, the limits of each sensor in detecting precipitation should be carefully analyzed in order to establish the degree of consistency of the precipitation patterns (and retrievals) obtained from different radiometers. A certain degree of coherence between different sensors can be accomplished by developing common procedures to be applied to all radiometers to detect efficiently the presence of precipitation in different environmental conditions. Consistency and accuracy are also the priorities in the development of our PMW precipitation retrieval algorithms used for the operational PMW precipitation products within the EUMETSAT "Satellite Application Facility on Support to Operational Hydrology and Water Management" (H-SAF) program (see Mugnai et al., 2013a). The H-SAF PMW algorithms for cross-track and conical-scanning radiometers are built upon the same physical foundations and use common procedures for the detection of precipitation (see Casella et al., 2013; Sanò et al., 2013, 2015; Mugnai et al., 2013b; Panegrossi et al., 2013).

Detection of precipitation from satellite observations using passive microwave radiometers is a difficult task, since the brightness temperatures emerging from precipitating clouds can be similar to those emitted by some surfaces in clear sky conditions. Precipitation detection is simpler over ocean because at the low-frequency channels $(10-30 \mathrm{GHz})$ the surface background appears relatively cold (in terms of brightness temperatures) due to the low and nearly uniform sea surface emissivity. This allows the detection of the absorp- tion/emission from large rain drops as relatively warm areas. Over land, the detection of precipitation is more complex as the rain-layer emission is obscured by the high emissivity of the background surface. The detection of precipitation still has some open issues (see Munchak and Skofronick-Jackson, 2013), especially over coast, arid regions, and over snowcovered surfaces. It is worth noting that some algorithms for precipitation estimation do not include specific procedures for the detection of precipitation and provide just a "probability of precipitation" (e.g., GPROF from version 7 of the TMIGPROF and in the GMI-GPROF; GPM, 2010). However, an accurate procedure for the detection of precipitation could be very useful within the estimation schemes in order to separate the problem of identifying the precipitating areas from the problem of estimating the intensity of the rainfall. Moreover, in the regions of the Earth where precipitation is infrequent (e.g., in semi-arid regions in the tropics), precipitation detection is crucial for drought monitoring. Over the last 20 years, different precipitation detection procedures have been widely used within precipitation retrieval algorithms.

It is quite common in the framework of precipitation estimates to refer to precipitation detection as "screening". Some widely used approaches are based on the scattering index (SI) over land surface (i.e., Grody, 1991; Ferraro, 1997). Another classical approach makes use of the polarization-corrected temperatures (Barrett et al., 1988; Spencer et al., 1989; Kidd, 1998; PCT). Unfortunately, these algorithms cannot be applied to the cross-track scanning radiometers (e.g., AMSUA, AMSU-B, MHS, ATMS), because they need both vertical and horizontal polarized channels at the same frequency. However, the most recent spaceborne radiometers utilize high-frequency channels $(150-160 \mathrm{GHz})$ and sounding channels in the $60 \mathrm{GHz}$ oxygen absorption band and the $183 \mathrm{GHz}$ water vapor absorption band. As a consequence, relatively new algorithms for the detection of precipitation have been developed (e.g., Chen and Staelin, 2003, using both the $52.3 \mathrm{GHz}$ channel and the $183 \mathrm{GHz}$ channels and Laviola and Levizzani, 2011, using the water vapor absorption band channels around $183 \mathrm{GHz}$ ). Recently more efforts have been made in solving the issue of detection of precipitation: among others, Grecu and Anagnostou (2001) applied a neural network approach, Seto et al. (2005) developed a lookup-database method, Laviola and Levizzani (2009) proposed a simple technique based upon a threshold on an AMSU-B channel combination, and Islam et al. (2014) have built a random forest classifier.

In this paper we will describe a precipitation detection algorithm based on canonical correlation analysis (CCA), hereafter referred to as the CCA algorithm. The novelty of the algorithm is that it is applicable to all available PMW radiometers in the GPM constellation, it is in principle very simple, and it is conditioned to the availability of a large data set of co-located measurements of multichannel TBs and quality-controlled precipitation measurements or estimates that can be considered as "truth". The algorithm was 
inspired by the approach of Petty (2013), who developed a methodology based on a two-stage principal component analysis aimed at reducing the dimensionality of the input in a Bayesian algorithm for the estimation of precipitation and "distilling" the relevant information from a multidimensional set of channels. The approach of Petty (2013) has been implemented and validated in two subsequent papers (Petty and $\mathrm{Li}, 2013 \mathrm{a}, 2013 \mathrm{~b})$. In this work we have modified and adapted the approach of Petty (2013) to the problem of precipitation detection using a simpler surface classification and without considering the linearization of the TBs into pseudochannels. We will show the CCA algorithm results and compare them to those obtained from different well-known precipitation detection schemes used within precipitation retrieval algorithms. The CCA algorithm described in this paper is currently applied to the PMW precipitation retrieval algorithms currently used to deliver operational products of instantaneous precipitation over European and African regions within the EUMETSAT H-SAF program (Mugnai et al., 2013a, 2013b; Casella et al., 2013; Sanò et al., 2013, 2015).

This paper is divided into five sections. Section 2 describes the data sets of co-located measurements of multichannel TBs from SSMIS and AMSU/MHS and precipitation measurements from the Tropical Rainfall Measuring Mission precipitation radar (TRMM-PR) used in the training data set of the CCA algorithm. A description of the procedures followed to separate the data set depending on the type of background surface is also provided. Section 3 illustrates the methodology used for the definition of the algorithm based on a training data set. Section 4 shows the results of the application of the algorithm to a separate test data set in terms of probability of detection (POD), falsealarm ratio (FAR) and Heidke skill score (HSS) with variable rain/no-rain thresholds. Results of the comparisons with other screening algorithms are also provided and the CCA performance is described in terms of minimum detectable rain and of total error for each background surface type. Finally Sect. 5 includes the summary of the main results and the conclusions.

\section{Instruments and data set description}

The study was carried out in the area between $36^{\circ} \mathrm{S}$ and $36^{\circ} \mathrm{N}$ in latitude and between $60^{\circ} \mathrm{E}$ and $60^{\circ} \mathrm{W}$ in longitude, covering the African continent, parts of the Arabian Peninsula, South America, and the Atlantic and Indian oceans. All the analyses were performed using coincident observations of the TRMM-PR with observations from SSMIS and AMSU/MHS radiometers for the years 2011-2013. The TRMM-PR was the first spaceborne precipitation radar; it provided publicly available data until October 2014 and can be considered the precursor to GPM DPR. It is a $13.8 \mathrm{GHz}$ radar scanning between -17 and $+17^{\circ}$ with a swath width of $247 \mathrm{~km}$ (after the satellite was boosted to higher orbit in 2001). SSMIS is a conical-scanning radiometer with a scanning angle of $45^{\circ}$ and a swath width of $1707 \mathrm{~km}$, measuring passive microwave radiation in 24 channels with frequencies ranging from 19 to $183 \mathrm{GHz}$. The 19,37 , and $91 \mathrm{GHz}$ channels are in the vertical and horizontal polarization, while the $22 \mathrm{GHz}$ channel is present only in the vertical polarization and the $150 \mathrm{GHz}$ is present only in the horizontal polarization as the channels in the water vapor absorption band (around $183.31 \mathrm{GHz}$ ). Finally, the channels in the oxygen absorption band $(50.3-63.2 \mathrm{GHz})$ are horizontally polarized (in the radiometer carried by the Defense Meteorological Satellite Program (DMSP) F16, channels 1-7 were incorrectly designed as $\mathrm{V}$ polarized) or right-circular polarized. The SSMIS radiometer is carried on board four satellites of the DMSP: the F16, F17, F18, and F19; the launch of F20 satellite is planned for 2020. AMSU-A and MHS are both cross-track scanning radiometers on board four satellites: NOAA-18, NOAA-19, Metop A, and Metop B. AMSUA has 23 channels between 23.8 and $89 \mathrm{GHz}$ while MHS has a channel at $89 \mathrm{GHz}$, at $157 \mathrm{GHz}$, and three channels in the $183 \mathrm{GHz}$ water vapor absorption band. The polarization measured by every channel changes with the scan angle which varies between -48.95 and $48.95^{\circ}$, and the swath width of the radiometer is about $1920 \mathrm{~km}$.

We selected all available coincidences (within a $15 \mathrm{~min}$ time window) of the SSMIS radiometer with the TRMM-PR in the area of interest considering the DMSP-F16 and DMSPF17 satellites (i.e., the DMSP-F18 has the $150 \mathrm{GHz}$ channel malfunctioning since February 2012). The same was done for the available AMSU/MHS radiometers for the Metop-A, NOAA-18, and NOAA-19 satellites. Therefore, two data sets have been created, one of SSMIS-PR coincidences and one of AMSU/MHS-PR coincidences, with a total of 3889 and 2581 coincident overpasses for the AMSU/MHS and for the SSMIS data set, respectively.

To obtain co-located vectors of SSMIS or AMSU/MHS TBs and PR rainfall estimates (TRMM product 2A25), the horizontal resolution variation with frequency in conically scanning MW radiometer (SSMIS) and with the observation angle in the cross-track scanning radiometers (AMSU/MHS) needs to be taken into account. Moreover, there are sampling differences between AMSU-A and MHS and between the SSMIS components (Imager, Environmental, Lower and Upper Atmospheric Sounder). Therefore, the TRMM-PR rainfall rate at the surface was downscaled to the SSMIS and MHS nominal resolution, defined as the IFOV size of the $91 \mathrm{GHz} / 89 \mathrm{GHz}$ channel for the SSMIS/MHS radiometer, respectively. All the channels with a coarser spatial grid were resampled using a nearest-neighbor approach; for the AMSU-A/MHS sensors we have used an IFOV size variable with the scan angle as described by Bennartz (2000).

The resulting data sets were divided into three classes depending on the background surface - land, ocean, and coast - using a digital land/sea map at $2 \mathrm{~s}$ of arc resolution. The 
land class was subdivided into vegetated land and arid land (desert). The arid land pixels have been identified by looking at the mean annual difference between the SSMIS $19 \mathrm{GHz} \mathrm{V}$ and $\mathrm{H}$ channels. Grody (1991) has shown how the difference of the $\mathrm{V}$ and $\mathrm{H}$ polarized channels is very effective in identifying desert. Although the presence of clouds may reduce the polarization difference, this effect may be minimized by averaging the TB difference over a long period. In this study we have looked at 1 year (2011) of SSMIS observations over the area of interest, selecting the observations over land, and remapping them on a regular grid in latitude and longitude (with $0.5^{\circ}$ spacing). The difference of the TBs of the $19 \mathrm{GHz} \mathrm{V}$ and $\mathrm{H}$ channels $\left(\mathrm{dTB}_{19}\right.$ ) was calculated for each grid point and then averaged over 1 year. The area corresponding to each grid point was identified as desert (or arid land) if the mean annual difference of $\mathrm{dTB}_{19}$ was higher than $15 \mathrm{~K}$ :

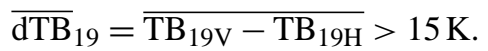

Figure 1 shows the results of this procedure over the area of interest. It is clear how the Sahara and the Arabian desert have been correctly identified as arid land. Smaller areas of arid land also appear in Iran (including the Dasht-e Kavir and the Dasht-e lut deserts) and over the African continent (including the Kalahari desert in southwest Africa and arid regions in the continental Horn of Africa). However, some small deserts near to the coast have been not correctly identified, i.e., the Namib in Namibia and the Danakil Desert on the African coast of the Red Sea. The coast pixels have been excluded from this test to eliminate the polarization difference due to the sea surface emissivity.

The SSMIS-PR and AMSU/MHS-PR data sets have been both divided into two separate data sets: a training set including all data from 2011 and 2012 and a test data set including data from 2013.

\section{Methodology}

This section is dedicated to the procedure used to define the CCA algorithm for which the training data set relative to the years 2011-2012 has been used. We have considered all channels of both data sets (AMSU/MHS and SSMIS) except the channels in the $50-60 \mathrm{GHz}$ band with a peak of the weighting function too high for the scope of this work, i.e., we have excluded the channels in the $50-60 \mathrm{GHz}$ band with a frequency higher than $55.5 \mathrm{GHz}$.

The first test was performed in order to select the combination of channels that is more suitable to discriminate the signal deriving from the precipitating cloud ("rain") from the signal deriving from the background surface ("no rain"). We call this monodimensional combination of channels the discriminant function. In order to obtain and test different discriminant functions we have applied two well-known multivariate methods: empirical orthogonal function (EOF) anal-

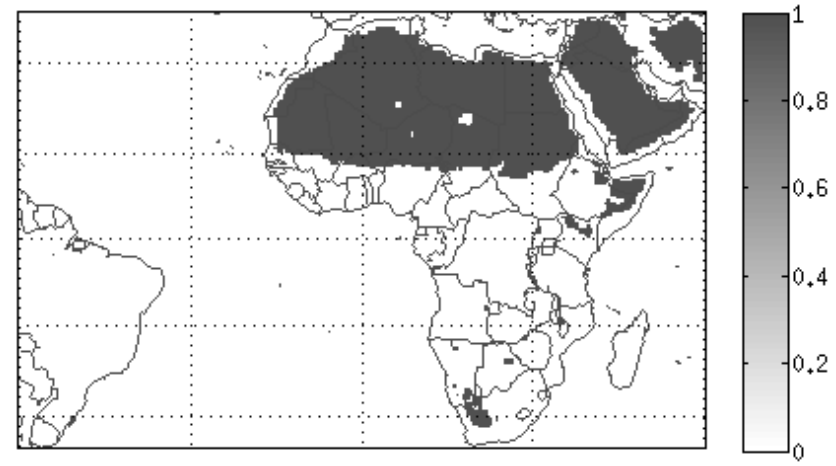

Figure 1. Map of arid land identified using the annual mean of the $19 \mathrm{GHz}$ channels difference (V-H). Dark grey areas are the regions identified as desert or arid land.

ysis and canonical correlation analysis (Wilks, 1995). Both procedures consist of a projection of a multidimensional space (TBs) in a new set of coordinates, and, while the principal components (resulting from an EOF analysis) are ordered by the increasing variance, the canonical variables (resulting from a CCA) are ordered by the correlation with a third variable (in our case the logarithm of the surface rainfall rate). We have calculated seven candidate discriminant functions and tested them in a simple discriminant analysis test. The test consisted in applying three multivariate statistical procedures either on the part of the data sets (SSMIS and AMSU/MHS) with precipitating pixels ("rain") or on the part of the data sets with non-precipitating pixels ("no rain") ("rain" or "no rain" pixel definitions are based on the TRMM-PR 2A25 product). The first procedure consisted of applying an EOF analysis on the TBs corresponding to "no rain" pixels, with the resulting combination of channels hereafter called $\mathrm{PCA}_{N}$. Once the principal components were calculated we discarded the first components (linked mostly to the signal deriving from the surface), in order to obtain a set of independent components (combination of TBs) with minimum signal coming from the surface. A second procedure consisted of applying an EOF analysis on the TBs corresponding to "rain" pixels, obtaining a combination of channels hereafter called $\mathrm{PCA}_{\mathrm{R}}$, and discarding the last components. A third procedure consisted of calculating the CCA on the "rain" fraction of the data set in order to select the linear combination of TBs with the maximum correlation to rainfall $\left(C C A_{R}\right)$. We have made comparisons with the results obtained performing the CCA with respect to $\log (R)$ (where $R$ is the rainfall rate) and to $R$, finding better performances for $\log (R)$. Therefore we have used the logarithm of rainfall rate as a reference variable for $C C A_{R}$. The objective of the last two procedures was to enhance the signal emitted by precipitating clouds. In the work of Petty (2013), two of these procedures $\left(\mathrm{PCA}_{\mathrm{N}}\right.$ and $\left.\mathrm{PCA} \mathrm{A}_{\mathrm{R}}\right)$ were applied to a data set of TBs in order to enhance the signal from precipitation and to mask the signal coming from the surface background. In this 
Table 1. Description of the seven-candidate discriminant functions.

\begin{tabular}{|c|c|c|c|}
\hline & Discriminant function & Short description & Comments/goal \\
\hline 1 & $\mathrm{PCA}_{\mathrm{N}}$ & EOF analysis on "no rain" pixels - first component chosen & To enhance the signal from the background surface \\
\hline 2 & $\mathrm{PCA}_{\mathrm{R}}$ & EOF analysis on "rain" pixels - first component chosen & To enhance the signal from precipitation. \\
\hline 6 & $\mathrm{PCA}_{\mathrm{R}}-\mathrm{CCA}_{\mathrm{R}}$ & $\begin{array}{l}\text { (1) EOF analysis of "rain" pixels - } \\
\text { discarding the last three components. } \\
\text { (2) CCA application to the selected } \\
\text { components - first canonical variable }\end{array}$ & $\begin{array}{l}\text { Same goal as row three. As suggested by Wilks (1995), CCA } \\
\text { is supposed to be more stable if applied to } \\
\text { selected components (eliminating those more } \\
\text { affected by random noise). }\end{array}$ \\
\hline
\end{tabular}

study we have tested seven candidate discriminate functions consisting of different combinations of the three procedures described above $\left(\mathrm{PCA}_{\mathrm{N}}, \mathrm{PCA}_{\mathrm{R}}\right.$ and $\left.\mathrm{CCA}_{\mathrm{R}}\right)$. Table 1 shows a synthetic description of the seven candidate discriminant functions.

The ability of each of the seven functions to discriminate the "rain" and "no rain" pixels has been tested with a simple linear discriminant analysis (Wilks, 1995). First, the SSMIS data set has been considered with a PR-based rain/norain threshold of $0.1 \mathrm{~mm} \mathrm{~h}^{-1}$ for each surface class. Then the same analysis was repeated for the AMSU/MHS data set (for each surface class). The choice of $0.1 \mathrm{mmh}^{-1}$ threshold for TRMM-PR was based on the evidence that the minimum detectable rain rate of this instrument, estimated by Kirstetter et al. (2014) as $0.53 \mathrm{~mm} \mathrm{~h}^{-1}$ at PR resolution, corresponds to the peak of the probability density function (pdf) of the rainfall rates in our data set at full resolution (not shown). By downscaling the PR rainfall rates to the SSMIS or MHS nominal resolution, the peak of the pdf of the rainfall rates shifts to lower values nearly equal to $0.1 \mathrm{~mm} \mathrm{~h}^{-1}$. The results in terms of Heidke skill score (which measures the fractional improvements over random chance) for the SSMIS data set are shown in Fig. 3. The HSS is defined as

$$
\mathrm{HSS}=\frac{2(h c-f m)}{(h+m)(m+c)+(h+f)(f+c)},
$$

where $h, m, f$, and $c$ are the fractional hits, misses, false detections, and correct rejections in a contingency table, respectively (Wilks, 1995). The HSS falls within a $[-\infty,+1]$ range, where 1 indicates the perfect score.

Looking at Fig. 2 it is clear how $\mathrm{PCA}_{N}$ and $\mathrm{PCA}_{\mathrm{R}}$ have relatively low skills over all background surfaces except for vegetated land. However, $\mathrm{CCA}_{\mathrm{R}}, \mathrm{PCA}_{\mathrm{R}}-\mathrm{CCA}_{\mathrm{R}}$, and $\mathrm{PCA}_{\mathrm{N}^{-}}$ $\mathrm{PCA}_{\mathrm{R}}-\mathrm{CCA}_{\mathrm{R}}$ have the best skill score over all surfaces and

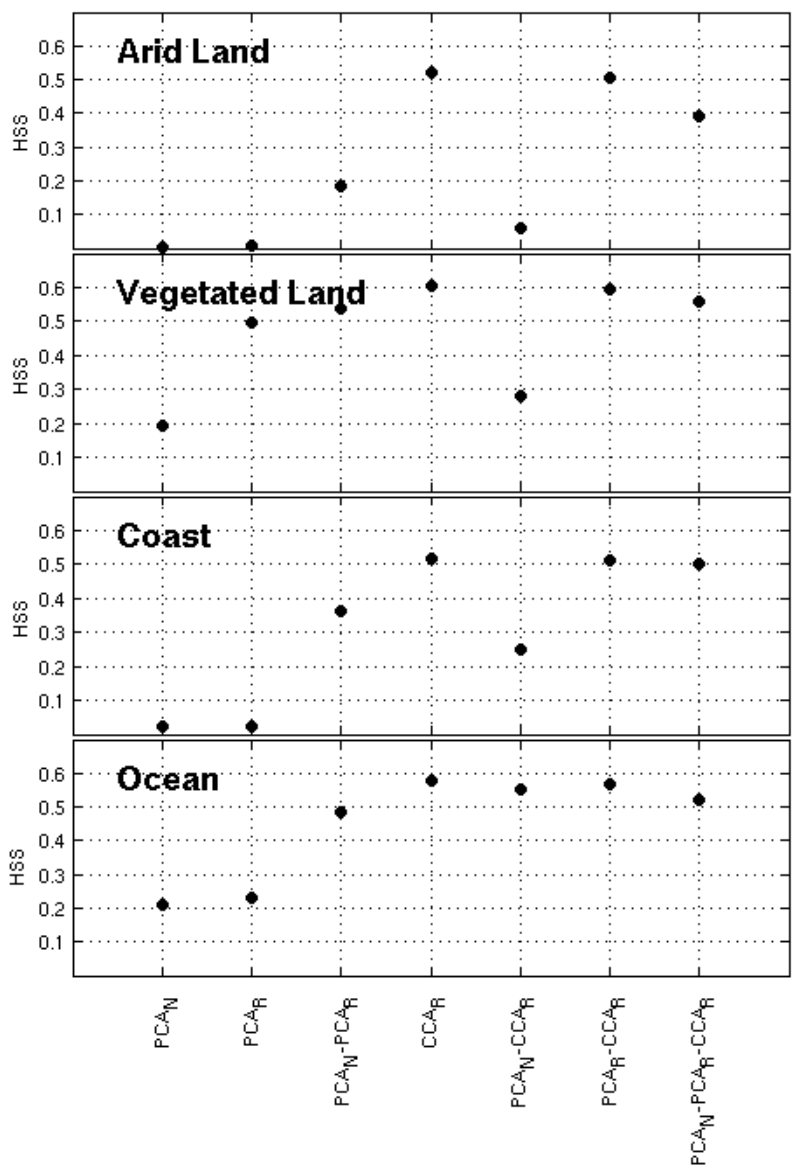

Figure 2. Results of the choice of the discriminant function over different background surface for the SSMIS data set: the labels of the $x$ axis identify the discriminant function used (see text for details) and the value represented in the $y$ axis is the Heidke skill score. 
behave quite similarly. Finally, $\mathrm{PCA}_{\mathrm{N}}-\mathrm{PCA}_{\mathrm{R}}$ and $\mathrm{PCA}_{\mathrm{N}^{-}}$ $\mathrm{CCA}_{R}$ have a skill variable depending on the surface type. $\mathrm{CCA}_{R}$ shows a high HSS and is a relatively simple procedure, being the result of a canonical correlation analysis on the TBs associated with rainfall as observed from the TRMM-PR. Similar results of the HSS were obtained for the AMSU/MHS data set. From the results of this analysis we have chosen the $\mathrm{CCA}_{R}$ as the discriminant function of the CCA algorithm for detection of precipitation.

The CCA algorithm was trained separately for the two data sets of coincidences of SSMIS with PR and coincidences of AMSU/MHS with PR using the full set of 2011-2012 observations. We have also tested how the detection algorithm would perform with a pseudo-GMI radiometer by selecting only the channels from the SSMIS data set more similar to those of the GMI radiometer (i.e., the SSMIS channels in the $50-60 \mathrm{GHz}$ absorption band and at $183 \pm 1 \mathrm{GHz}$ were discarded).

The CCA algorithm has been defined in two steps for each of the three data sets (SSMIS-PR, AMSU/MHS-PR, and pseudo GMI-PR) and considering the four different background surface types. First, we have carried out the $C_{C A}$ (i.e., on the TBs of "rain" pixels) to find the coefficients $\left(a_{i}\right)$ of the linear combination of TB channels best correlated to precipitation (canonical variables, $\mathrm{CV}$ ), defined as

$$
\mathrm{CV}=\sum_{i=1}^{n} a_{i}\left(\mathrm{~TB}^{i}-\overline{\mathrm{TB}}_{m}^{i}\right)
$$

where the index $i$ spans over the $n$ available channels of the radiometer (SSMIS, AMSU/MHS, or pseudo-GMI), TB ${ }^{i}$ is the brightness temperature in each pixel, and $\overline{\mathrm{TB}}_{\mathrm{R}}^{i}$ is the mean brightness temperature over the full "rain" data set. Then, we found the threshold value of $\mathrm{CV}$ to discriminate between "rain" and "no rain" pixels $\left(\mathrm{CV}_{\text {th }}\right)$. This was computed by analyzing the variability of HSS over the full data set for different threshold values $\mathrm{CV}_{\text {th }}$ (ranging between -2 and $8 \mathrm{~K}$ ), using the TRMM-PR rainfall product as "truth" with minimum "rain" threshold of $0.1 \mathrm{~mm} \mathrm{~h}^{-1}$. The threshold value $\mathrm{CV}_{\text {th }}$, which maximizes the HSS, was selected. This procedure was repeated for each surface background and radiometer data set. Therefore, for each surface and for each radiometer a set of coefficients $a_{i}$ and a threshold value $\mathrm{CV}_{\text {th }}$ was determined to discriminate between "rain" and "no rain" pixels.

The CCA algorithm marks those pixels as "rain" where

$\mathrm{CV}=\sum_{i=1}^{n} a_{i}\left(\mathrm{~TB}^{i}-\overline{\mathrm{TB}}_{\mathrm{R}}^{i}\right)>\mathrm{CV}_{\mathrm{th}}$.

The resulting coefficient of the $\mathrm{CCA}_{\mathrm{R}}$ analysis $\left(a_{i}\right)$ and the chosen threshold $\mathrm{CV}_{\text {th }}$ are therefore defined for each radiometer (SSMIS, AMSU/MHS, or pseudo-GMI) and for each type of surface background, and they are summarized in Appendix A.

\section{Results}

This section shows the results of the application of the algorithm to the test data set relative to the year 2013. In the tuning of the algorithms we classified the precipitating pixels adopting an arbitrary rainfall rate threshold of $0.1 \mathrm{mmh}^{-1}$; however, it is possible that in some conditions the radiometric signal is not suited to detect such light precipitation. Moreover, an algorithm for the detection of precipitation is always a compromise between the need for detecting the lower minimum threshold of rain rate and the requirement of low detection errors in terms of both false alarms and misses. In this section we analyze the results of the CCA algorithm for different rainfall rate thresholds $\left(\mathrm{RR}_{\mathrm{th}}\right)$, using the TRMM-PR 2A25 product as ground truth for "rain" pixels. We compare the results with those obtained from widely used screening algorithms (presented in Sect. 1), applying them on the same data sets used for the CCA algorithm. In particular, we have used four other procedures: (1) the scattering index (Ferraro, 1997), hereafter F97-SI, i.e., the scattering index over land and ocean considering also the estimated columnar water vapor from 19 to $37 \mathrm{GHz}$ over ocean; (2) the polarization-corrected temperature algorithm from Spencer et al. (1989) (hereafter SGH-PCT) in which the PCT is calculated with $\beta=0.45$, considering the pixels with $\mathrm{PCT}<255 \mathrm{~K}$ as "rain"; (3) the AMSU/MHS screening algorithm from Chen and Staelin (2003), which uses differences between the $183 \mathrm{GHz}$ channels and the $53.6 \mathrm{GHz}$ and applicable over each type of surface background considered in this study (hereafter CS03); and (4) the methodology developed by Grody and Weng (2008) and employed by many authors (e.g., Laviola and Levizzani, 2009, 2011), which uses the TB difference between the MHS channels at $89 \mathrm{GHz}$ (or SSMIS and GMI-like $91.6 \mathrm{GHz}$ ) and $150 \mathrm{GHz}$ as a simple mask in order to detect the scattering signal from precipitation (hereafter GW08). The "rain" threshold on this TB difference has been set to $5 \mathrm{~K}$. Table 2 summarizes the screening algorithms used for comparison in this study.

The results are evaluated in terms of HSS, POD, and FAR, defined as

$\mathrm{POD}=\frac{h}{(h+m)} ; \quad \mathrm{FAR}=\frac{f}{(f+h)}$,

with the same reference to a contingency table as in Eq. (3).

\subsection{Discussion of skill scores}

Figures 3 and 4 show the results for the SSMIS (and pseudoGMI) data sets and for the AMSU/MHS data sets, respectively, for all types of surface background. All tested algorithms have higher POD for higher $R_{\text {th }}$ because high rain rates are usually associated with precipitating clouds with a strong radiometric signal (except in some cases such as warm rain over land). It is worth noting, however, that the impact on the TBs in the different microwave channels depends on several factors, such as the surface background, environmental 
Table 2. Algorithms used for comparison in the study. * Used only for SSMIS and pseudo-GMI data sets.

\begin{tabular}{lll}
\hline Acronym & Brief description & Reference \\
\hline F97-SI* & $\begin{array}{l}\text { Scattering index over land and ocean using 19 and } \\
\text { 22 GHz and estimated IWV over ocean using 37 GHz. }\end{array}$ & Ferraro (JGR, 1997) \\
\hline SGH-PCT* & $\begin{array}{l}\text { Polarization-corrected temperature (PCT) algorithm; } \\
\text { we have calculated the PCT with } \beta=0.45, \\
\text { considering the pixels with PCT < 255 K as "rain". }\end{array}$ & Spencer et al. (JAOT, 1989) \\
& $\begin{array}{l}\text { Considers differences between the 183 GHz channels and } \\
\text { the 53.6 GHz and is applicable over each type of surface } \\
\text { background considered in this study. }\end{array}$ & Chen and Staelin (TGRS, 2003) \\
\hline CS03 & $\begin{array}{l}\text { TB difference between the MHS channel at 89 GHz } \\
\text { (or 91.6 GHz for SSMIS and pseudo-GMI) and 150 GHz } \\
\text { to detect the scattering signal from precipitation. }\end{array}$ & Grody and Weng (TGRS, 2008) \\
&
\end{tabular}
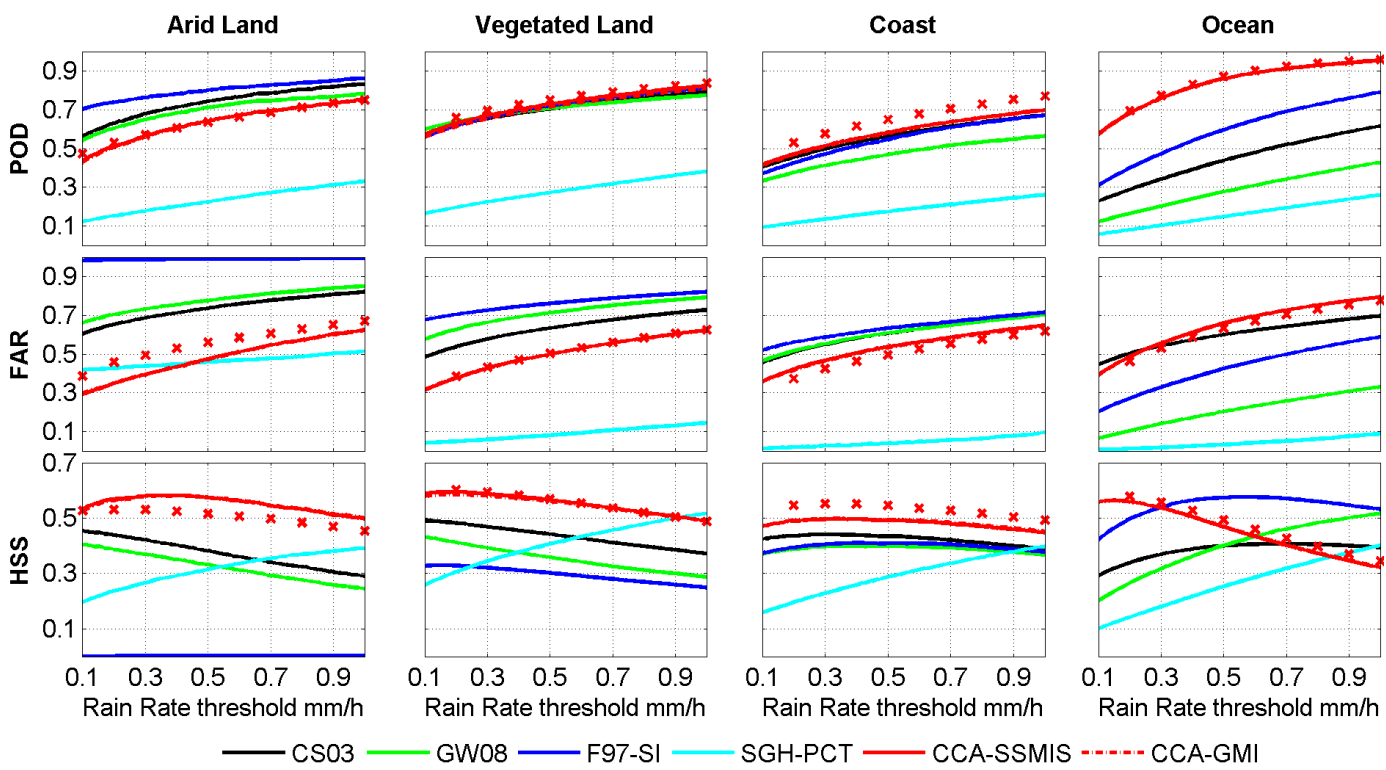

Figure 3. Comparison of the CCA-SSMIS and CCA-GMI algorithms with other similar algorithms for the detection of precipitation using the PR rain rate with a variable threshold (represented in the $x$ axis) as ground truth for the precipitating pixels. The results are shown in four columns of panels (one for each surface type) in terms of POD (upper row of panels), FAR (middle row), and HSS (lower row). The scales are the same for every plot. Solid lines show the statistical indexes resulting from the application of a screening algorithm to the test data set (year 2013); red crosses are the result of the application of the SSMIS-CCA algorithm to the training data set (years 2011-2012).

and meteorological conditions, and the microphysical structure of the cloud. FAR grows with $\mathrm{RR}_{\mathrm{th}}$ as well in all of the algorithms considered, as a consequence of the fact that by increasing $\mathrm{RR}_{\mathrm{th}}$ the size of the areas considered as precipitating by the TRMM-PR is reduced, while the areas identified as "rain" by the detection schemes are unchanged. The overall performance of the detection schemes can be evaluated by looking at the HSS (last row in each figure).

In Fig. 3, over every surface the CCA algorithm applied to SSMIS and pseudo-GMI (CCA-SSMIS and CCA-GMI) shows almost identical scores. Moreover, the comparison of the scores of CCA-SSMIS on the training data set (red crosses in Fig. 4) and test data set (continuous red line) shows a good agreement between the two, a sign of the stability of the algorithm. Over arid land, vegetated land, and coast the CCA-SSMIS performs better (i.e., higher HSS) than the other algorithms especially due to lower FAR. The SGH-PCT shows a low POD and a low FAR over all surface background types. The major drawback of the SGH-PCT algorithm is that it needs to use both polarizations of the SSMIS (or pseudoGMI) $91 \mathrm{GHz}$ channels, and, therefore, it is not applicable to AMSU/MHS or other cross-track scanning radiometers. It is also worth noting that the F97-SI algorithm is not suited for detecting precipitation over desert (arid land) because the use 

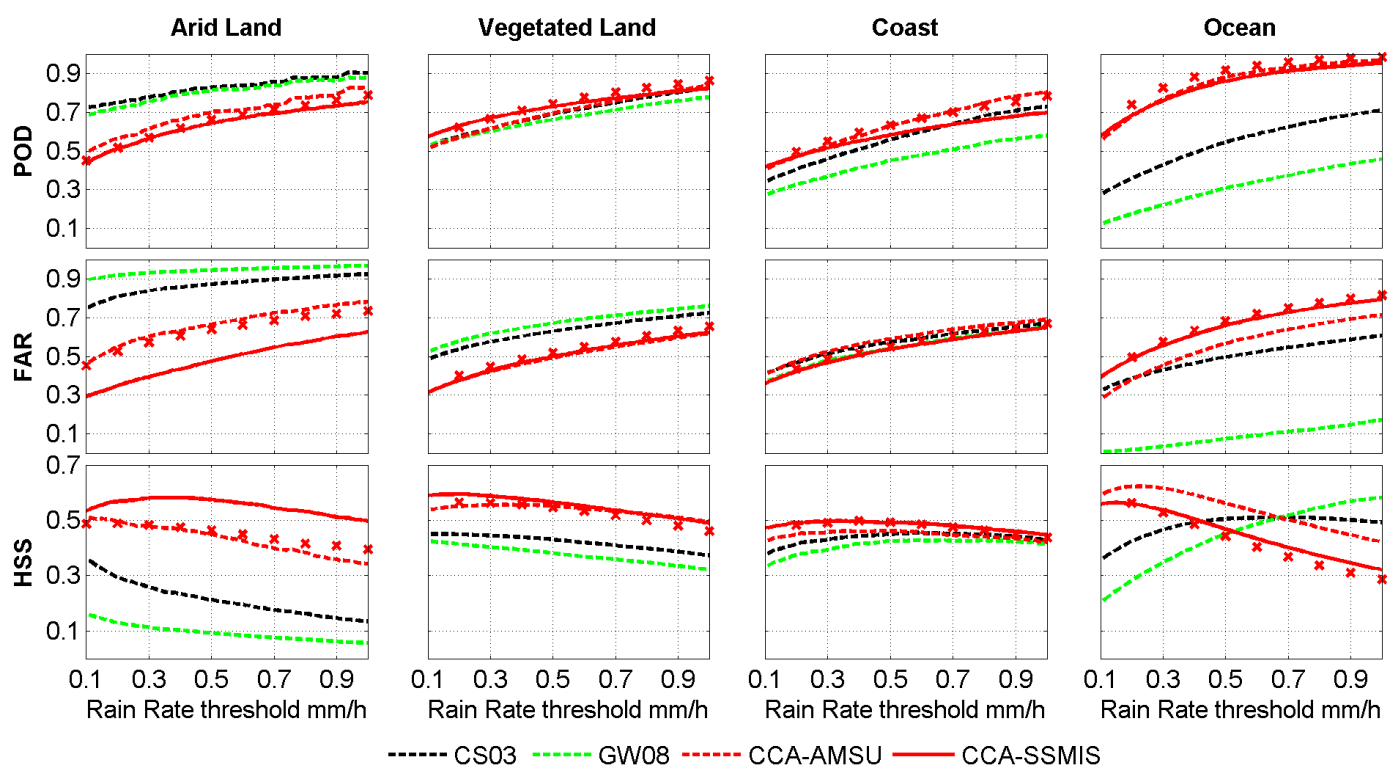

Figure 4. Same as Fig. 3 but for the AMSU/MHS data set. The CCA-SSMIS (red solid curve) (results of the CCA algorithm applied to SSMIS test data set shown in Fig. 3) are shown here for comparison. Red crosses are the result of the application of the CCA-AMSU algorithm to the training data set (years 2011-2012).

of the SI leads to the misclassification of the signal deriving from the surface as precipitation (in fact it was not applied to desert background in the original work by Ferraro, 1997). Over ocean, the CCA algorithms have higher POD than the others (while the FAR is comparable to CS03). Over ocean, CCA-SSMIS and CCA-GMI show higher HSS than the other algorithms except the F97-SI, which has higher HSS for $\mathrm{RR}_{\text {th }}$ larger than $0.3 \mathrm{~mm} \mathrm{~h}^{-1}$. We can conclude that over ocean the CCA algorithm is more suitable to detect low precipitation rates $\left(\mathrm{RR}_{\mathrm{th}} \leq 0.2 \mathrm{~mm} \mathrm{~h}^{-1}\right)$ than the F97-SI; however, F97-SI is preferable to detect higher precipitation rates.

Figure 4 shows that the CCA-AMSU has a behavior similar to the CCA-SSMIS (CCA-GMI). No results for F97-SI and SGH-PCT are presented in this figure because these two approaches can not be applied to the AMSU/MHS radiometers, since the $19 \mathrm{GHz}$ channel and the two polarization of the $89 \mathrm{GHz}$ are not available. Over arid and vegetated land, the CCA-AMSU performs better than the other algorithms (higher HSS due to the significantly lower FAR). Over coast, the CCA-AMSU has skill scores very similar to the other algorithms. Finally, over ocean the CS03 and GW08 seem to work better (in terms of HSS) for high values of $R_{\text {th }}$.

A complete and synthetic representation of the skill scores for all algorithms but for one rain rate threshold $\left(0.1 \mathrm{~mm} \mathrm{~h}^{-1}\right)$ is provided in Fig. 5 (CCA-GMI results have been omitted because they are identical to CCA-SSMIS scores). From this figure it is evident how the CCA algorithm, both for AMSU/MHS and for SSMIS, performs well in terms of HSS with respect to the other tested algorithms and how this is due to the higher POD and to the lower FAR.

\subsection{Minimum detectable rate}

This section is dedicated to defining the minimum detectable rainfall rate for the CCA algorithm for each surface type and sensor and to computing the statistical scores of the algorithm for these thresholds. Figure 6 shows the results of a binning technique (following Ferraro and Marks, 1995) applied to the TRMM-PR rainfall rate corresponding to the CV values (Eq. 4) of each pixel. For each data set (i.e., for SSMIS, AMSU/MHS and pseudo-GMI and for four different types of surface) the CV range of values has been divided into bins $0.2 \mathrm{~K}$ wide, and the mean and the standard deviation of the TRMM-PR rainfall rate corresponding to each $\mathrm{CV}$ value has been calculated for each bin. Each panel shows the trend of the mean rainfall rate (and standard deviation) with the CV binned values. A thick vertical dashed line represents the $\mathrm{CV}$ threshold chosen for each radiometer and surface background type as a result of the CCA training (i.e, $\mathrm{CV}_{\text {th }}$ in Eq. 5, Sect. 3; the values are also provided in Appendix A).

Looking at the trend of mean rain rate with $\mathrm{CV}$ and at the rain rate standard deviation it is evident that increasing values of $\mathrm{CV}$ are on average associated with increasing values of rainfall rate. All the pixels falling in the bins below $\mathrm{CV}_{\text {th }}$ are misclassified as "no rain" and they correspond to the low rainfall values (below $0.5 \mathrm{~mm} \mathrm{~h}^{-1}$ for all the data sets). We have considered the minimum detectable rainfall rate for each data set $\left(\mathrm{RR}_{b}\right)$ as the mean value corresponding to the $\mathrm{CV}_{\text {th. }}$. In Table 3 the values of $\mathrm{RR}_{b}$ are reported and the scores of the CCA algorithm based on these thresholds are also provided. It is clear from Fig. 6 and Table 3 how the 


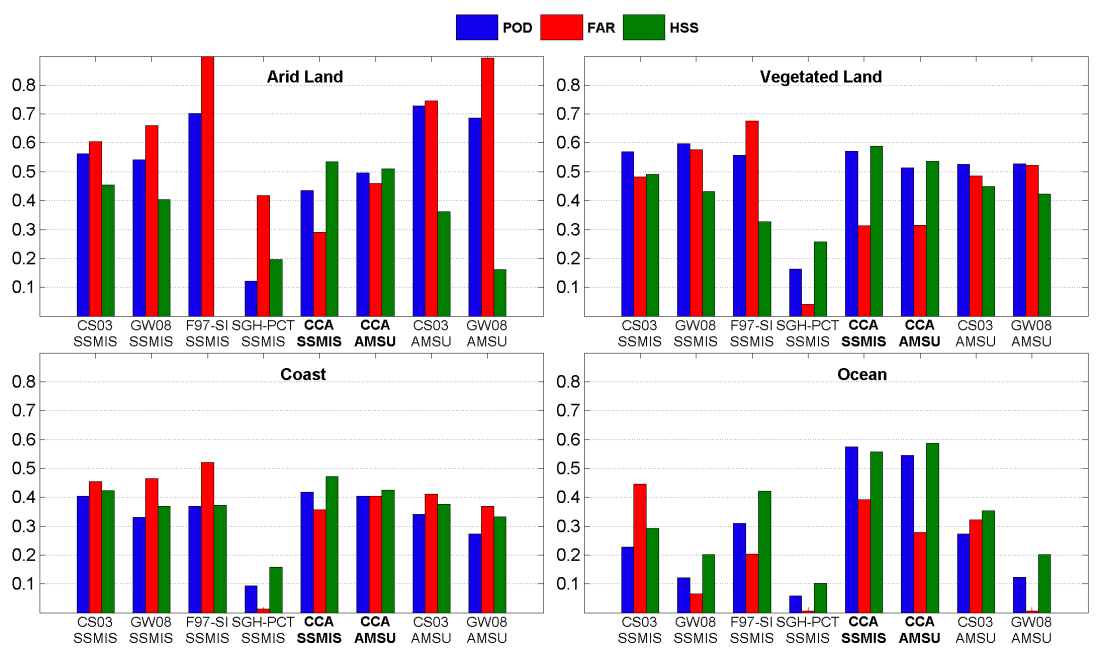

Figure 5. Skill score comparison of the CCA algorithm with other precipitation detection algorithms with rain/no-rain threshold ("truth" from PR 2A25) equal to $0.1 \mathrm{mmh}^{-1}$.
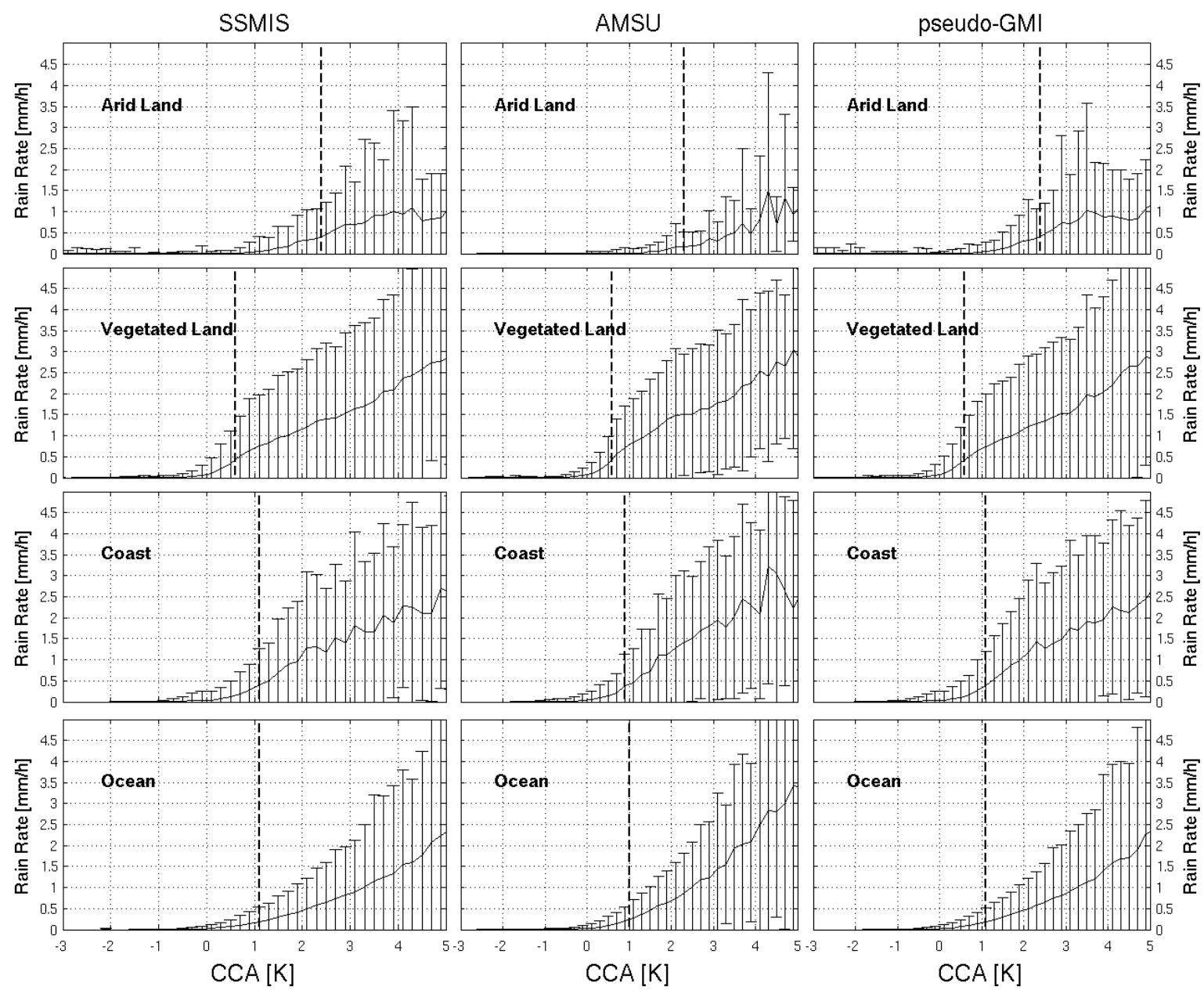

Figure 6. Binning analysis of the rain rate intensity against CV values: mean (continuous black line) and standard deviation (error bars) of rain rates inside an interval of $\mathrm{CV}$ bins (as large as $0.2 \mathrm{~K}$ ) are shown. The vertical dashed line represents the $\mathrm{CV}$ threshold (CVth) chosen for each combination of radiometer and surface background. 
Table 3. Value of the mean rain rate corresponding to the CCA threshold set for every radiometer and surface background combination. Values in bold refer to the test data set while the italics values refer to the training data set.

\begin{tabular}{|c|c|c|c|c|c|c|c|c|c|c|c|c|}
\hline & \multicolumn{4}{|c|}{ SSMIS } & \multicolumn{4}{|c|}{ AMSU/MHS } & \multicolumn{4}{|c|}{ GMI } \\
\hline & $\begin{array}{l}\text { Arid } \\
\text { land }\end{array}$ & $\begin{array}{l}\text { Veg. } \\
\text { land }\end{array}$ & Coast & Ocean & $\begin{array}{l}\text { Arid } \\
\text { land }\end{array}$ & $\begin{array}{l}\text { Veg. } \\
\text { land }\end{array}$ & Coast & Ocean & $\begin{array}{l}\text { Arid } \\
\text { land }\end{array}$ & $\begin{array}{l}\text { Veg. } \\
\text { land }\end{array}$ & Coast & Ocean \\
\hline $\mathrm{RR}_{\mathrm{th}}\left(\mathrm{mmh}^{-1}\right)$ & 0.25 & 0.35 & 0.41 & 0.18 & 0.26 & 0.31 & 0.24 & 0.14 & 0.33 & 0.38 & 0.40 & 0.18 \\
\hline POD & 0.57 & 0.74 & 0.62 & 0.68 & 0.56 & 0.73 & 0.61 & 0.71 & 0.60 & 0.73 & 0.62 & 0.67 \\
\hline$\left(\mathrm{RR}_{\mathrm{th}}\right)$ & 0.61 & 0.71 & 0.55 & 0.67 & 0.55 & 0.69 & 0.57 & 0.72 & 0.60 & 0.71 & 0.54 & 0.67 \\
\hline FAR & 0.50 & 0.49 & 0.47 & 0.45 & 0.55 & 0.52 & 0.57 & 0.47 & 0.51 & 0.50 & 0.47 & 0.44 \\
\hline$\left(\mathrm{RR}_{\mathrm{th}}\right)$ & 0.44 & 0.49 & 0.50 & 0.47 & 0.52 & 0.51 & 0.58 & 0.43 & 0.44 & 0.50 & 0.50 & 0.47 \\
\hline HSS & 0.53 & 0.57 & 0.55 & 0.58 & 0.49 & 0.53 & 0.45 & 0.56 & 0.53 & 0.56 & 0.54 & 0.58 \\
\hline$\left(\mathrm{RR}_{\mathrm{th}}\right)$ & 0.58 & 0.56 & 0.50 & 0.56 & 0.50 & 0.53 & 0.42 & 0.61 & 0.58 & 0.55 & 0.50 & 0.56 \\
\hline
\end{tabular}

CCA performs better over vegetated land and over ocean for both SSMIS and AMSU, and $\mathrm{RR}_{b}$ is lower over ocean (less than $0.2 \mathrm{~mm} \mathrm{~h}^{-1}$ ) and higher over land (around $0.3 \mathrm{mmh}^{-1}$ ). Over arid land it is possible to discriminate lower values of rain intensity (around $0.25 \mathrm{~mm} \mathrm{~h}^{-1}$ ) but the strong variability in the surface emissivity leads to a higher ratio of misses (lower POD). Over coast the results are quite different between the SSMIS and the AMSU algorithms: the $\mathrm{RR}_{b}$ over coast for the SSMIS is the highest among all the data sets $\left(0.41 \mathrm{~mm} \mathrm{~h}^{-1}\right)$, while the irregular trend of the mean rain rate over coast for the AMSU/MHS makes the result for $\mathrm{RR}_{b}$ over coast $\left(0.24 \mathrm{~mm} \mathrm{~h}^{-1}\right)$ uncertain.

Regarding the pseudo-GMI data set, it is worth noting that it was generated from the SSMIS data set only by discarding the channels not available in the GMI radiometer $(183 \pm 1$ and the $50-60 \mathrm{GHz}$ band channels). Therefore, the results are only to a certain extent representative of the performance of a CCA algorithm for the real GMI radiometer, since we have considered only the instrument observation geometry (conical scanning) and some of the channels frequencies and polarizations. The presence of the 10 and $166 \mathrm{GHz}$ channels with both polarizations (not available on SSMIS) might have a significant impact on precipitation detection. Moreover, the differences in the resolution of the GMI and SSMIS sensors have not been considered, and this may strongly affect the results on real GMI data. It is worth noting that the almost identical results obtained for the SSMIS and pseudo-GMI data sets indicate that the inclusion of the sounding channels $183 \pm 1$ and $50-60 \mathrm{GHz}$ has no impact on the precipitation detection.

\subsection{Dependence on precipitation regime}

In the following subsection we have analyzed the CCA algorithm scores using the rainType flag as estimated by TRMM product 2A23 (please refer to TRMM, 2011, for details on the rainType flag definitions in the TRMM-PR 2A23 prod- uct). Each PR pixel has been classified into four main rain categories as

1. stratiform (rainType $\geq 100$ and $<200$ )

2. convective (rainType $\geq 200$ and $<250$ )

3. shallow convective (rainType $\geq 250$ and $<300$ )

4. other (rainType $\geq 300$ ).

In the test data sets this information was downscaled to the SSMIS and MHS nominal resolutions by calculating the fraction of PR precipitating pixels corresponding to each rain category within each SSMIS and AMSU/MHS pixel. Each pixel in the SSMIS-PR and AMSU/MHS-PR data sets has been classified as mainly convective if at least $50 \%$ of the precipitating part of the pixel was convective. The same criterion was adopted for the other rain categories. If a pixel was classified as precipitating with no predominance of any of the main rain type class, it was flagged as mixed.

Table 4 shows the POD score for each rain type class and for each surface background. Moreover, Table 5 shows the POD calculated as a function of the fraction of precipitation in the pixel (for all surface background classes together). It is clear from Tables 4 to 5 that the CCA algorithm detects convective and stratiform precipitation very well, while it is almost insensitive to shallow precipitation over land and coast and gives medium performances (between 0.30 and 0.58 ) for other and mixed precipitation types. However, from Table 5 it is evident that the detection capability of precipitation grows with the fraction of precipitation within the SSMIS and MHS pixels. These results indicate that the non-uniform beam filling effect can have a significant impact on the detection of the precipitation, and the impact depends on the predominant type of precipitation within each pixel (i.e, the most significant impact for shallow precipitation, the least significant for stratiform precipitation, and quite significant for convective precipitation). 
Table 4. Probability of detection scores classified by surface background and rain type.

\begin{tabular}{|c|c|c|c|c|c|c|}
\hline & & \multicolumn{5}{|c|}{ POD } \\
\hline & & Convective & Stratiform & Shallow & Other & Mixed \\
\hline \multirow{4}{*}{$\sum_{\tilde{n}}^{\infty}$} & Arid land & 0.61 & 0.68 & - & 0.30 & 0.33 \\
\hline & Veg. land & 0.76 & 0.84 & 0.08 & 0.55 & 0.48 \\
\hline & Coast & 0.68 & 0.82 & 0.09 & 0.39 & 0.36 \\
\hline & Ocean & 0.84 & 0.93 & 0.42 & 0.48 & 0.55 \\
\hline \multirow{4}{*}{ 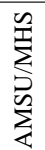 } & Arid land & $0.73^{*}$ & 0.77 & - & $0.44^{*}$ & $0.33^{*}$ \\
\hline & Veg. land & 0.76 & 0.84 & $0.07^{*}$ & 0.45 & 0.47 \\
\hline & Coast & 0.75 & 0.87 & 0.09 & 0.30 & 0.38 \\
\hline & Ocean & 0.89 & 0.96 & 0.40 & 0.38 & 0.58 \\
\hline
\end{tabular}

* sample $100-500$ pixels.

Table 5. Probability of detection scores classified by rain type and percentage of precipitation in the pixel. No results are provided for samples with less than 100 pixels.

\begin{tabular}{|c|c|c|c|c|c|c|}
\hline & \multirow[b]{2}{*}{$\begin{array}{l}\text { Fraction } \\
\text { of precip. }\end{array}$} & \multicolumn{5}{|c|}{ POD with fraction of precipitation } \\
\hline & & Convective & Stratiform & $\begin{array}{c}\text { Shallow } \\
\text { conv. }\end{array}$ & Other & Mixed \\
\hline \multirow{9}{*}{$\sum_{\tilde{n}}^{\infty}$} & $>0.1$ & 0.75 & 0.87 & 0.38 & 0.47 & 0.53 \\
\hline & $>0.2$ & 0.77 & 0.88 & 0.44 & 0.47 & 0.53 \\
\hline & $>0.3$ & 0.79 & 0.88 & 0.47 & 0.47 & 0.57 \\
\hline & $>0.4$ & 0.81 & 0.89 & 0.49 & 0.49 & 0.62 \\
\hline & $>0.5$ & 0.82 & 0.91 & 0.51 & 0.56 & 0.69 \\
\hline & $>0.6$ & 0.84 & 0.92 & 0.54 & 0.59 & 0.71 \\
\hline & $>0.7$ & 0.84 & 0.93 & 0.61 & 0.57 & 0.81 \\
\hline & $>0.8$ & 0.88 & 0.95 & 0.68 & 0.63 & 0.90 \\
\hline & $>0.9$ & 0.89 & 0.96 & 0.71 & 0.70 & 0.92 \\
\hline \multirow{9}{*}{ 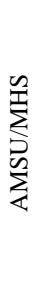 } & $>0.1$ & 0.79 & 0.89 & 0.28 & 0.40 & 0.52 \\
\hline & $>0.2$ & 0.81 & 0.90 & 0.32 & 0.41 & 0.57 \\
\hline & $>0.3$ & 0.84 & 0.91 & 0.36 & 0.45 & 0.64 \\
\hline & $>0.4$ & 0.87 & 0.93 & 0.44 & 0.57 & 0.70 \\
\hline & $>0.5$ & 0.91 & 0.95 & 0.57 & 0.73 & 0.81 \\
\hline & $>0.6$ & 0.93 & 0.96 & 0.59 & 0.81 & 0.88 \\
\hline & $>0.7$ & 0.97 & 0.97 & $0.70^{*}$ & 0.84 & 0.94 \\
\hline & $>0.8$ & 0.99 & 0.98 & $0.75^{*}$ & $0.88^{*}$ & 0.98 \\
\hline & $>0.9$ & 1.00 & 0.99 & - & - & 1.00 \\
\hline
\end{tabular}

Table 6 shows the results for the false alarms considering the actual potential presence of rain in the AMSU/MHS and SSMIS pixel based on the downscaled PR rain/no-rain flag values (2A23 rainFlag). The first column shows the FAR scores for each surface type, while the other columns show the percentage of false alarms counts (for each surface type) for three different classes of rain/no-rain conditions. The three classes are as follows.

1. Low rain: SSMIS or AMSU/MHS pixels classified as "rain certain" (rainFlag equals to 20). For this class, CCA false alarms refer to PR downscaled rain rates less than $0.1 \mathrm{mmh}^{-1}$.

2. Potential rain: SSMIS or AMSU/MHS pixels classified as "rain possible" or "probable" (rainFlag between 10 and 15). For this class, false alarms refer to PR down-
Table 6. False alarms ratio scores classified by surface and rain flag. Percentages represent the fraction of false alarm counts for a given surface type and rainFlag w.r.t the total number of false alarms for each surface type.

\begin{tabular}{|c|c|c|c|c|c|}
\hline & & \multicolumn{4}{|c|}{ False alarms } \\
\hline & & $\begin{array}{l}\text { Total } \\
\text { FAR }\end{array}$ & $\begin{array}{c}\text { Low } \\
\text { rain } \\
\%\end{array}$ & $\begin{array}{c}\text { Potential } \\
\text { rain } \\
\%\end{array}$ & $\begin{array}{c}\text { No rain } \\
\%\end{array}$ \\
\hline \multirow{4}{*}{$\sum_{\tilde{n}}^{\infty}$} & Arid land & 0.29 & 29.03 & 52.23 & 18.74 \\
\hline & Veg. land & 0.31 & 27.15 & 49.25 & 23.60 \\
\hline & Coast & 0.36 & 27.03 & 45.95 & 27.03 \\
\hline & Ocean & 0.39 & 29.58 & 35.07 & 35.35 \\
\hline \multirow{4}{*}{$\sum_{\substack{\infty \\
\infty}}^{\infty}$} & Arid land & 0.46 & 39.27 & 57.58 & 3.16 \\
\hline & Veg. land & 0.32 & 48.75 & 45.76 & 5.49 \\
\hline & Coast & 0.40 & 55.16 & 38.57 & 6.27 \\
\hline & Ocean & 0.28 & 59.57 & 33.77 & 6.66 \\
\hline
\end{tabular}

scaled rain rates equal to $0 \mathrm{~mm} \mathrm{~h}^{-1}$. This class includes very weak echoes (possibly noise) and non-precipitating clouds.

3. No rain: SSMIS or AMSU/MHS pixels classified as "no rain" " (rainFlag equals to 0 ).

It is clear from Table 6 that only a relatively small percentage of the false alarms are associated with "no rain" pixels (especially for AMSU/MHS ranging between 3 and $6 \%$ ), while a quite significant number of the false alarms are associated with "low rain" PR observations with low rain rates (for the SSMIS 27-30\% and for AMSU/MHS 39-60\%).

\section{Conclusions}

The CCA algorithm for the detection of precipitation described in this paper results from the application of two main procedures: (1) the application of the canonical correlation analysis to a large data set of coincident PMW multichannel observations and precipitation measurements or estimates, which can be considered as "truth" to define canonical variables for different types of surface background; (2) the estimation of a threshold value for the canonical variables that maximizes the Heidke skill score for a given rainfall rate threshold. The algorithm has been applied to three large data sets built from coincident SSMIS and AMSU/MHS measurements and TRMM-PR rainfall products (SSMISPR, AMSU/MHS-PR, and pseudo-GMI-PR). Four different types of surface background have been considered, and the results have been compared to other well-known screening algorithms. The resulting CCA algorithm is simple, and it can be adapted to any PMW radiometer and to any geographical region where a large data set of coincident precipitation 
measurements and PMW observations from that radiometer is available.

The CCA algorithm almost always shows better performance in comparison to other well-known algorithms, especially in terms of low false-alarm ratios. The HSS is always higher than all other algorithms tested, except for AMSU/MHS over ocean for high rainfall rate thresholds $>0.7 \mathrm{~mm} \mathrm{~h}^{-1}$ and SSMIS over ocean for rainfall rate thresholds $>0.3 \mathrm{~mm} \mathrm{~h}^{-1}$. The estimate of the minimum rain rate that is efficiently detected by the algorithm shows values varying from $0.14 \mathrm{~mm} \mathrm{~h}^{-1}$ (AMSU/MHS over ocean) to 0.41 (SSMIS over coast) with the remarkable result of $0.25 \mathrm{~mm} \mathrm{~h}^{-1}$ over arid land surface. It is worth noting that the pseudo-GMI data set was generated by selecting the channels available in the GMI radiometer from the SSMIS data set. Therefore, the results from the pseudo-GMI data set need to be looked at with some caution. The geometry of observation of the two instruments is very similar and the polarization and frequency of the selected channels almost coincide. However, the presence of the 10 and $166 \mathrm{GHz}$ channels with both polarizations (not available on SSMIS) might have a significant impact on precipitation detection. In this study the almost identical results obtained for the SSMIS and pseudoGMI data sets are more related to the significance of the oxygen band absorption channels for light precipitation detection. Our results indicate that the inclusion of the sounding channels $183 \pm 1$ and $50-60 \mathrm{GHz}$ has almost no impact on precipitation detection.

An analysis of the results based on different precipitation regimes (as identified by the TRMM-PR) has shown how the CCA algorithm has very high detection capability for convective and stratiform precipitation. Shallow convective precipitation detection efficiency strongly depends on the surface background as CCA is almost insensitive to shallow convective rain over coast and land and gives moderate performances over ocean. Moreover, the results show that the non-uniform beam filling effect can have a significant impact on the detection of precipitation, and the impact depends on the precipitation regime, i.e, highest for shallow precipitation, lowest for stratiform precipitation, and quite significant for convective precipitation.

The CCA algorithm for the different radiometers (i.e., CCA-AMSU, and CCA-SSMIS) seems to perform well, with a good detection capability and low false alarms ratios. It is worth noting that only a relatively small percentage of the CCA false alarms are related to totally rain-free pixels, while a quite significant contribution comes from pixels with very low rain rates, i.e., downscaled PR rain rates lower than the minimum rain/no-rain threshold used $\left(0.1 \mathrm{~mm} \mathrm{~h}^{-1}\right)$.

The advent of the GPM era requires the combined use of different PMW radiometers with different channels and dissimilar observation geometry for global precipitation monitoring. This poses a difficult challenge to the scientific community, i.e., the obtaining of coherent estimates of precipitation from this constellation of radiometers. Much effort is put into achieving consistency between precipitation pattern and precipitation estimates from the different sensors. Some fundamental improvements in this direction will come from the use of common procedures applicable to all radiometers for the detection (and the retrieval) of precipitation, applicable to all types of background surfaces. The CCA algorithm is an important step toward this goal, considering it is suitable for application to any PMW sensor (conical and cross-track scanning) for which a long time series of data coincidences with rainfall rate considered as ground truth is available.

The results show a certain level of consistency between the detection capability of CCA-SSMIS and CCA-AMSU algorithms. It is worth noting that by using different thresholds and linear combinations of channels for each sensor, the algorithm optimally exploits the characteristics of each sensor. However, the available channels, polarization information, spatial resolutions, and observation geometry, which differ from radiometer to radiometer, introduce fundamental variations in the precipitation detection capabilities of each sensor and pose intrinsic limitations to the level of achievable consistency. In the EUMETSAT H-SAF project, the consistency of the precipitation estimates between cross-track and conical scanning radiometers has been strongly improved by the use a common procedure for the detection of the precipitating clouds (besides the use of the same physical foundation in the retrieval algorithms; see Mugnai et al., 2013b; Panegrossi et al., 2013).

In the near future we plan to develop the CCA algorithm for GMI, GCOM-W1 AMSR2, and Suomi NPP ATMS. We are planning to take advantage of the imminent availability of the GPM DPR products in order to extend and test the CCA procedure between $65^{\circ} \mathrm{N}$ and $65^{\circ} \mathrm{S}$, especially over snow- and ice-covered surfaces. Moreover, the estimates of the CloudSat Profiling Radar may be used as ground truth (especially for snowfall and light precipitation) in order to create an even larger data set of coincident observations of active and passive MW satellite-borne instruments and extend the CCA algorithm to higher latitudes and to the polar regions. 


\section{Appendix A}

Tables A1-3 show the $\mathrm{CV}$ thresholds $\left(\mathrm{CV}_{\text {th }}\right)$, the coefficients, and mean TB values used by the CCA algorithms for the SSMIS, pseudo-GMI, and AMSU/MHS data sets. The mean TBs in the pseudo-GMI data set are identical to the corresponding channels of the SSMIS data set.

Table A1. List of CCA coefficients and CVth thresholds used by the CCA algorithms for the SSMIS radiometer.

\begin{tabular}{|c|c|c|c|c|c|c|c|c|c|}
\hline \multicolumn{2}{|c|}{$\begin{array}{l}\text { SSMIS } \\
\mathrm{CV}_{\text {th }}\end{array}$} & \multicolumn{2}{|c|}{$\begin{array}{c}\text { Arid land } \\
2.4 \mathrm{~K}\end{array}$} & \multicolumn{2}{|c|}{$\begin{array}{c}\text { Vegetated land } \\
0.6 \mathrm{~K} \\
\end{array}$} & \multicolumn{2}{|c|}{$\begin{array}{l}\text { Coast } \\
1.1 \mathrm{~K} \\
\end{array}$} & \multicolumn{2}{|c|}{$\begin{array}{c}\text { Ocean } \\
1.1 \mathrm{~K} \\
\end{array}$} \\
\hline Ch. \# & $\begin{array}{l}\text { Ch. name } \\
(\mathrm{GHz})\end{array}$ & $\mathrm{a}$ & $\overline{\mathrm{TB}}_{\mathrm{R}}$ & $\mathrm{a}$ & $\overline{\mathrm{TB}}_{\mathrm{R}}$ & $\mathrm{a}$ & $\overline{\mathrm{TB}}_{\mathrm{R}}$ & $\mathrm{a}$ & $\overline{\mathrm{TB}}_{\mathrm{R}}$ \\
\hline 1 & 150 & -0.07 & 274.86 & -0.08 & 277.65 & -0.05 & 277.39 & -0.01 & 277.49 \\
\hline 2 & $183 \pm 6.6$ & -0.11 & 272.51 & -0.02 & 267.49 & -0.04 & 270.66 & 0.00 & 271.99 \\
\hline 3 & $183 \pm 3$ & 0.01 & 263.31 & 0.03 & 259.86 & 0.03 & 262.60 & -0.00 & 263.73 \\
\hline 4 & $183 \pm 1$ & 0.04 & 249.90 & -0.01 & 247.08 & 0.00 & 249.52 & 0.00 & 249.70 \\
\hline 5 & $91.6 \mathrm{~V}$ & -0.04 & 280.53 & -0.01 & 280.98 & -0.04 & 274.12 & 0.04 & 266.26 \\
\hline 6 & $91.6 \mathrm{H}$ & 0.07 & 268.41 & 0.06 & 278.17 & 0.04 & 258.09 & -0.03 & 240.88 \\
\hline 7 & $19 \mathrm{H}$ & 0.03 & 260.61 & 0.03 & 278.43 & -0.02 & 210.99 & -0.05 & 144.39 \\
\hline 8 & $19 \mathrm{~V}$ & 0.01 & 290.69 & 0.02 & 284.46 & -0.04 & 246.96 & 0.01 & 205.56 \\
\hline 9 & $22.2 \mathrm{~V}$ & 0.02 & 290.24 & 0.03 & 285.60 & 0.05 & 263.45 & -0.01 & 237.66 \\
\hline 10 & $37 \mathrm{H}$ & -0.02 & 262.77 & -0.03 & 276.90 & 0.03 & 219.56 & 0.08 & 164.45 \\
\hline 11 & $37 \mathrm{~V}$ & -0.03 & 285.72 & -0.02 & 281.13 & -0.02 & 251.85 & 0.10 & 220.26 \\
\hline 12 & 50.3 & 0.02 & 275.23 & -0.04 & 275.60 & -0.00 & 262.59 & -0.01 & 249.79 \\
\hline 13 & 52.8 & 0.02 & 265.73 & -0.01 & 265.05 & -0.00 & 264.08 & -0.02 & 262.26 \\
\hline 14 & 53.6 & 0.03 & 249.90 & 0.01 & 249.96 & 0.01 & 249.91 & -0.02 & 249.40 \\
\hline 15 & 54.4 & 0.00 & 217.64 & 0.01 & 217.72 & 0.01 & 216.62 & 0.00 & 217.05 \\
\hline 16 & 55.5 & 0.02 & 211.21 & -0.01 & 210.19 & -0.00 & 210.87 & 0.00 & 211.17 \\
\hline
\end{tabular}

Table A2. List of CCA coefficient and CVth threshold used by the CCA algorithms for the pseudo-GMI data set.

\begin{tabular}{|c|c|c|c|c|c|}
\hline \multicolumn{2}{|c|}{ GMI } & Arid & Vegetated & Coast & Ocean \\
\hline \multicolumn{2}{|c|}{$\mathrm{CV}_{\text {th }}$} & $2.4 \mathrm{~K}$ & $0.6 \mathrm{~K}$ & $1.1 \mathrm{~K}$ & $1.1 \mathrm{~K}$ \\
\hline Ch. \# & $\begin{array}{l}\text { Ch. name } \\
(\mathrm{GHz})\end{array}$ & $\mathrm{a}$ & $\mathrm{a}$ & A & $\mathrm{a}$ \\
\hline 1 & 150 & -0.06 & 274.86 & -0.08 & 277.65 \\
\hline 2 & $183 \pm 6.6$ & -0.12 & 272.51 & -0.02 & 267.49 \\
\hline 3 & $183 \pm 3$ & 0.06 & 263.31 & 0.02 & 259.86 \\
\hline 5 & $91.6 \mathrm{~V}$ & -0.04 & 280.53 & -0.01 & 280.98 \\
\hline 6 & $91.6 \mathrm{H}$ & 0.07 & 268.41 & 0.05 & 278.17 \\
\hline 7 & $19 \mathrm{H}$ & 0.04 & 260.61 & 0.03 & 278.43 \\
\hline 8 & $19 \mathrm{~V}$ & 0.03 & 290.69 & 0.01 & 284.46 \\
\hline 9 & $22.2 \mathrm{~V}$ & 0.03 & 290.24 & 0.03 & 285.60 \\
\hline 10 & $37 \mathrm{H}$ & -0.03 & 262.77 & -0.03 & 276.90 \\
\hline 11 & $37 \mathrm{~V}$ & -0.03 & 285.72 & -0.03 & 281.13 \\
\hline
\end{tabular}


Table A3. List of CCA coefficient and CVth threshold used by the CCA algorithms for the AMSU/MHS data set.

\begin{tabular}{|c|c|c|c|c|c|c|c|c|c|}
\hline \multicolumn{2}{|c|}{$\begin{array}{c}\text { AMSU A-MHS } \\
\mathrm{CV}_{\text {th }}\end{array}$} & \multicolumn{2}{|c|}{$\begin{array}{c}\text { Arid land } \\
2.3 \mathrm{~K}\end{array}$} & \multicolumn{2}{|c|}{$\begin{array}{c}\text { Vegetated land } \\
0.6 \mathrm{~K}\end{array}$} & \multicolumn{2}{|c|}{$\begin{array}{l}\text { Coast } \\
0.9 \mathrm{~K} \\
\end{array}$} & \multicolumn{2}{|c|}{$\begin{array}{l}\text { Ocean } \\
1.0 \mathrm{~K}\end{array}$} \\
\hline Ch.\# & Ch. name $(\mathrm{GHz})$ & $\mathrm{a}$ & $\overline{\mathrm{TB}}_{\mathrm{R}}$ & $\mathrm{a}$ & $\overline{\mathrm{TB}}_{\mathrm{R}}$ & $\mathrm{a}$ & $\overline{\mathrm{TB}}_{\mathrm{R}}$ & a & $\overline{\mathrm{TB}}_{\mathrm{R}}$ \\
\hline 1 & 89 & 0.04 & 284.02 & 0.06 & 285.49 & 0.04 & 263.60 & 0.08 & 239.74 \\
\hline 2 & 150 & -0.06 & 285.12 & -0.05 & 284.45 & -0.08 & 282.53 & -0.04 & 279.56 \\
\hline 3 & $183.3 \pm 1$ & 0.03 & 253.96 & -0.03 & 250.97 & 0.01 & 253.00 & -0.02 & 254.31 \\
\hline 4 & $183.3 \pm 3$ & 0.05 & 267.25 & 0.08 & 263.62 & 0.02 & 265.74 & 0.05 & 267.37 \\
\hline 5 & $183.3 \pm 7$ & -0.17 & 278.89 & -0.11 & 273.11 & -0.05 & 275.31 & -0.01 & 276.41 \\
\hline 6 & 23.8 & 0.01 & 285.72 & 0.04 & 286.06 & 0.06 & 239.15 & -0.04 & 187.14 \\
\hline 7 & 31.4 & -0.02 & 284.17 & -0.00 & 283.86 & -0.06 & 226.90 & 0.10 & 166.38 \\
\hline 8 & 50.3 & 0.01 & 284.84 & -0.06 & 283.49 & 0.01 & 258.43 & -0.02 & 231.73 \\
\hline 9 & 52.8 & 0.02 & 276.40 & -0.04 & 274.62 & -0.00 & 269.23 & -0.08 & 262.65 \\
\hline 10 & 53.6 & 0.04 & 261.16 & 0.03 & 260.27 & -0.00 & 259.34 & -0.05 & 257.62 \\
\hline 11 & 54.4 & 0.04 & 240.45 & 0.05 & 240.38 & -0.00 & 240.43 & 0.02 & 239.96 \\
\hline 12 & 54.9 & 0.02 & 230.14 & 0.04 & 229.96 & -0.01 & 230.11 & 0.06 & 229.86 \\
\hline 13 & 55.5 & -0.03 & 216.91 & -0.03 & 216.33 & -0.02 & 216.60 & 0.13 & 216.54 \\
\hline
\end{tabular}


Acknowledgements. The authors would like to thank NOAA (www.nsof.class.noaa.gov) for providing the AMSU-A/MHS and SSMIS radiometers data and NASA (trmm.gsfc.nasa.gov) for providing the TRMM data. The authors express appreciation to Stephen Joseph Munchak and two anonymous reviewers for helpful comments and suggestions that have contributed to significantly improve the manuscript. This research was supported by EUMETSAT through the project "Satellite Application Facility on Support to Operational Hydrology and Water Management" (H-SAF).

Edited by: S. J. Munchak

\section{References}

Barrett, E. C., Kidd, C., and Bailey, J. O.: A new instrument with rainfall monitoring potential, Int. J. Remote Sens., 9, 1943-1950, 1988.

Bennartz, R.: Optimal convolution of amsu-b to amsu-a, J. Atmos. Ocean. Tech., 17, 1215-1225, 2000.

Casella, D., Panegrossi, G., Sano, P., Dietrich, S., Mugnai, A., Smith, E. A., Tripoli, G. J., Formenton, M., Di Paola, F., and Leung, W.-Y.: Transitioning from CRD to CDRD in Bayesian retrieval of rainfall from satellite passive microwave measurements: Part 2. Overcoming database profile selection ambiguity by consideration of meteorological control on microphysics, IEEE T. Geosci. Remote, 51, 4650-4671, 2013.

Chen, F. W. and Staelin, D. H.: Airs/amsu/hsb precipitation estimates, IEEE T. Geosci. Remote, 41, 410-417, 2003.

Desbois, M., Roca, R., Eymar L., Viltard, N., Viollier, M., Srinivasan, J., and Narayanan, S.: The Megha-Tropiques mission, in: Atmospheric and Oceanic Processes, Dynamics, and Climate Change, edited by: Sun, Z., Jin, F.-F., and Iwasaki, T., International Society for Optical Engineering, SPIE P., 4899, 172-183, doi:10.1117/12.466703, 2003

Edward, P. and Pawlak, D.: MetOp: The space segment for EUMETSAT's polar system, ESA Bulletin, 102, 6-18, 2000.

Ferraro, R. R.: Special sensor microwave imager derived global rainfall estimates for climatological applications, J. Geophys. Res., 102, 16715-16735, doi:10.1029/97jd01210, 1997.

Ferraro, R. R. and Marks, G. F.: The development of SSM/I rain-rate retrieval algorithms using ground-based radar measurements, J. Atmos. Ocean. Tech., 12, 755-770, 1995.

GPM: Algorithm Theoretical Basis Document, NASA, available at: http://pmm.nasa.gov/sites/default/files/document_files/ GPROF_ATBD_1Dec2010.pdf, last access: 7 September 2014, 2010.

Grecu, M. and Anagnostou, E. N.: Overland precipitation estimation from TRMM passive microwave observations, J. Appl. Meteorol., 40, 1367-1380, 2001.

Grody, N. C.: Classification of snow cover and precipitation using the Special Sensor Microwave Imager, J. Geophys. Res., 96, 7423-7435, doi:10.1029/91JD00045, 1991.

Grody, N. C. and Weng, F.: Microwave emission and scattering from deserts: theory compared with satellite measurements, IEEE T. Geosci. Remote, 46, 361-375, 2008.

Hou, A. Y., Kakar, R. K., Neeck, S., Azarbarzin, A. A., Kummerow, C. D., Kojima, M., Oki, R., Nakamura, K., and Iguchi, T.:
The global precipitation measurement mission, B. Am. Meteorol. Soc., 95, 701-722, doi:10.1175/BAMS-D-13-00164.1, 2014

Islam, T., Rico-Ramirez, M. A., Srivastava, P. K., and Dai, Q.: Non-parametric rain/no rain screening method for satellite-borne passive microwave radiometers at $19-85 \mathrm{GHz}$ channels with the Random Forests algorithm, Int. J. Remote Sens., 35, 3254-3267, 2014.

Kidd, C.: On rainfall retrieval using polarization-corrected temperatures, Int. J. Remote Sens., 19, 981-996, 1998.

Kirstetter, P. E., Hong, Y., Gourley, J., Schwaller, M., Petersen, W., and Cao, Q.: Impact of sub-pixel rainfall variability on spaceborne precipitation estimation: evaluating the TRMM 2A25 product, Q. J. Roy. Meteor. Soc., doi:10.1002/qj.2416, online first, 2014.

Kummerow, C. D., Hong, Y., Olson, W., Yang, S., Adler, R., McCollum, J., Ferraro, R., Petty, G., Shin, D.-B., and Wilheit, T.: The evolution of the Goddard profiling algorithm (GPROF) for rainfall estimation from passive microwave sensors, J. Appl. Meteorol., 40, 1801-1820, 2001.

Kummerow, C. D., Ringerud, S., Crook, J., Randel, D., and Berg, W.: An observationally generated a priori database for microwave rainfall retrievals, J. Atmos. Ocean. Tech., 28, 113-130, 2011.

Kunkee, D. B., Poe, G. A., Boucher, D. J., Swadley, S. D., Hong, Y., Wessel, J. E., and Uliana, E. A.: Design and evaluation of the first special Sensor Microwave Imager/Sounder, IEEE T. Geosci. Remote, 46, 863-883, doi:10.1109/tgrs.2008.917980, 2008.

Laviola, S. and Levizzani, V.: Observing precipitation by means of water vapor absor tion lines: a first check of the retrieval capabilities of $\mathrm{p}$ the 183-WSL rain retrieval method, Riv. Ital. Telerilevam., 41, 39-49, 2009.

Laviola, S. and Levizzani, V.: The 183-WSL fast rain rate retrieval algorithm: Part I: Retrieval design, Atmos. Res., 99, 443-461, 2011.

Mugnai, A., Casella, D., Cattani, E., Dietrich, S., Laviola, S., Levizzani, V., Panegrossi, G., Petracca, M., Sanò, P., Di Paola, F., Biron, D., De Leonibus, L., Melfi, D., Rosci, P., Vocino, A., Zauli, F., Pagliara, P., Puca, S., Rinollo, A., Milani, L., Porcù, F., and Gattari, F.: Precipitation products from the hydrology SAF, Nat. Hazards Earth Syst. Sci., 13, 1959-1981, doi:10.5194/nhess-13-1959-2013, 2013a.

Mugnai, A., Smith, E. A., Tripoli, G. J., Bizzarri, B., Casella, D., Dietrich, S., Di Paola, F., Panegrossi, G., and Sanò, P.: CDRD and PNPR satellite passive microwave precipitation retrieval algorithms: EuroTRMM/EURAINSAT origins and $\mathrm{H}-$ SAF operations, Nat. Hazards Earth Syst. Sci., 13, 887-912, doi:10.5194/nhess-13-887-2013, 2013b.

Munchak, S. J. and Skofronick-Jackson, G.: Evaluation of precipitation detection over various surfaces from passive microwave imagers and sounders, Atmos. Res., 131, 81-94, 2013.

Muth, C., Webb, W. A., Atwood, W., and Lee, P.: Advanced technology microwave sounder on the National PolarOrbiting Operational Environmental Satellite System, in: Geoscience and Remote Sensing Symposium, 25-29 July 2005. IGARSS '05. Proceedings. 2005 IEEE International, 1, 4 pp., doi:10.1109/IGARSS.2005.1526113, 2005.

Panegrossi, G., Casella, D., Dietrich, S., Sanò, P., Petracca, M., and Mugnai, A.: A verification study over Europe of AMSU-A/MHS and SSMIS passive microwave precipitation retrievals, Proc. 
2013 Joint EUMETSAT/AMS Meteorological Satellite Conference, 8 pp., 2013.

Petty, G. W.: Dimensionality reduction in Bayesian estimation algorithms, Atmos. Meas. Tech., 6, 2267-2276, doi:10.5194/amt6-2267-2013, 2013.

Petty, G. W. and Li, K.: Improved Passive Microwave Retrievals of Rain Rate over Land and Ocean. Part I: Algorithm Description, J. Atmos. Ocean. Tech., 30, 2493-2508, doi:10.1175/jtech-d-1200144.1, 2013a.

Petty, G. W. and Li, K.: Improved Passive Microwave Retrievals of Rain Rate over Land and Ocean. Part II: Validation and Intercomparison, J. Atmos. Ocean. Tech., 30, 2509-2526, doi:10.1175/jtech-d-12-00184.1, 2013b.

Sanò, P., Casella, D., Mugnai, A., Schiavon, G., Smith, E. A., and Tripoli, G. J.: Transitioning from CRD to CDRD in Bayesian retrieval of rainfall from satellite passive microwave measurements: Part 1. Algorithm description and testing, IEEE T. Geosci. Remote, 51, 4119-4143, 2013.

Sanò, P., Panegrossi, G., Casella, D., Di Paola, F., Milani, L., Mugnai, A., Petracca, M., and Dietrich, S.: The Passive microwave Neural network Precipitation Retrieval (PNPR) algorithm for AMSU/MHS observations: description and application to European case studies, Atmos. Meas. Tech., 8, 837-857, doi:10.5194/amt-8-837-2015, 2015.
Seto, S., Takahashi, N., and Iguchi, T.: Rain/no-rain classification methods for microwave radiometer observations over land using statistical information for brightness temperatures under no-rain conditions, J. Appl. Meteorol., 44, 1243-1259, doi:10.1175/JAM2263.1, 2005.

Shimoda, H.: GCOM missions, Geoscience and Remote Sensing Symposium, 2005. IGARSS '05. Proceedings. 2005 IEEE International, 25-29 July, Seoul, South Korea, 6, 4201-4204, doi:10.1109/IGARSS.2005.1525844, 2005.

Spencer, R. W., Goodman, H. M., and Hood, R. E.: Precipitation retrieval over land and ocean with the SSM/I: identification and characteristics of the scattering signal, J. Atmos. Ocean. Tech., 6, 254-273, 1989.

TRMM: Tropical Rainfall Measuring Mission (TRMM) Precipitation Radar Algorithm - Instruction Manual For Version 7, JAXA-NASA, www.eorc.jaxa.jp/TRMM/documents/PR algorithm_product_information/pr_manual/PR_Instruction_ Manual_V7_L1.pdf, last access: March 2015, 2011.

Wilheit, T. T.: Comparing calibrations of similar conically scanning window-channel microwave radiometers, IEEE T. Geosci. Remote, 51, 1453-1464, 2013.

Wilks, D. S.: Statistical methods in the atmospheric sciences: An introduction, Academic Press, San Diego, 1995. 